\title{
Implementation of the aortic no-touch technique to reduce stroke after off-pump coronary surgery
}

\author{
Alexander Albert, MD, PhD, ${ }^{\mathrm{a}}$ Jürgen Ennker, MD, PhD, ${ }^{\mathrm{b}, \mathrm{c}}$ Yasser Hegazy, MD, ${ }^{\mathrm{d}, \mathrm{e}}$ Sebastian Ullrich, ${ }^{\mathrm{f}}$ \\ Georgi Petrov, MD, ${ }^{\mathrm{a}}$ Payam Akhyari, MD, PhD, ${ }^{\mathrm{a}}$ Stefan Bauer, MD, PhD, ${ }^{\mathrm{d}}$ Eda Ürer, ${ }^{\mathrm{a}}$ \\ Ina Carolin Ennker, $\mathrm{MD}, \mathrm{PhD},{ }^{\mathrm{g}}$ Artur Lichtenberg, $\mathrm{MD}, \mathrm{PhD},{ }^{\mathrm{a}}$ Horst Priss, $\mathrm{MD},{ }^{\mathrm{h}}$ and \\ Alexander Assmann, MD, $\mathrm{PhD}^{\mathrm{a}, \mathrm{i}}$
}

\section{ABSTRACT}

Objectives: Despite substantial scientific effort, the relationship between stroke after coronary artery bypass grafting and the use of the aortic no-touch offpump technique (anOPCAB) remains incompletely understood. The present study aimed to define the effect of anOPCAB on the occurrence and time point of stroke.

Methods: A total cohort of 15,042 consecutive patients underwent surgical myocardial revascularization at a single institution. After establishing anOPCAB as routine procedure, 4695 patients received surgery by 18 different surgeons using the anaortic approach. After the exclusion of all patients with cardiogenic shock and "side-clamp" off-pump coronary artery bypass grafting, 13,279 patients (4485 with anOPCAB) were included in the study. Perioperative strokes were classified as strokes occurring during the hospital stay, with early strokes observed immediately after emergence from anesthesia (vs delayed strokes).

Results: The anOPCAB technique reduced the postoperative stroke rate to $0.49 \%$ versus $1.31 \%$ in on-pump patients $(P<.0001)$. The overall stroke rate after adoption of anOPCAB $(0.64 \%)$ decreased compared with before its adoption $(1.40 \% ; P<.0001)$. With anOPCAB, the risk of early strokes virtually disappeared to 4 of 4485 patients $(0.09 \% ; 95 \%$ confidence interval, $0.00-0.18 \%$ vs $0.83 \%$ in on-pump patients; $P<.0001$ ), whereas the incidence of delayed strokes was not affected $(0.40 \%$ vs $0.48 \% ; P=.5181)$. The key results were confirmed after adjustment using propensity score-based analyses.

Conclusions: The anOPCAB technique with avoidance of any aortic manipulation is an effective tool to minimize the risk of early strokes during coronary artery bypass grafting, and thus, should be considered as a routine approach. In contrast, additional preventive strategies against delayed strokes remain to be elaborated. (J Thorac Cardiovasc Surg 2018;156:544-54)

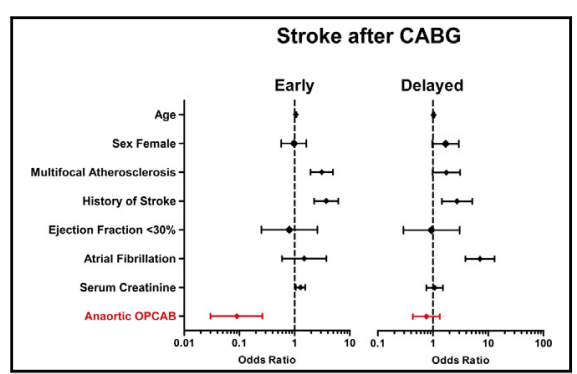

Risk factors for early and delayed stroke after coronary artery bypass grafting.

\section{Central Message}

The anaortic off-pump coronary artery bypass grafting technique minimizes the early stroke risk toward $0.1 \%$, whereas the elimination of delayed postoperative strokes requires alternative approaches.

\section{Perspective}

Because the anaortic off-pump coronary artery bypass grafting technique is shown to be suitable for the whole risk spectrum of coronary surgery patients and to approximate the early stroke risk toward $0.1 \%$, it should be considered as a routine approach. Although the quest for prevention of early strokes seems to be solved, future research should focus on the reduction of delayed strokes.

See Editorial Commentary page 555.

\footnotetext{
From the a Department of Cardiovascular Surgery and Research Group for Experimental Surgery, Heinrich Heine University, Medical Faculty, Duesseldorf, Germany; ${ }^{b}$ Department of Cardiac Surgery, University Clinic Oldenburg, Oldenburg, Germany; ${ }^{c}$ Faculty of Health, School of Medicine, University of Witten Herdecke, Witten, Germany; ${ }^{\mathrm{d}}$ Department of Cardiac, Thoracic, and Vascular Surgery, MediClin Heart Center Lahr/Baden, Lahr/Baden, Germany; ${ }^{\mathrm{e}}$ Department of Cardio-Thoracic Surgery, Faculty of Medicine, Alexandria University, Alexandria, Egypt; ${ }^{\mathrm{f}}$.05 Statistics Consultants, Life Science Centre, Duesseldorf, Germany; ${ }^{\mathrm{g}}$ Department of Plastic, Aesthetic-, Hand- and Reconstructive Surgery, Hannover Medical School, Hannover, Germany; ${ }^{\mathrm{h}}$ Department of Neurology, Ortenau Clinic, Lahr-Ettenheim, Germany; and ${ }^{\mathrm{i}}$ Biomaterials Innovation Research Center, Department of Medicine, Brigham and Women's Hospital, Harvard Medical School, Boston, Mass.
}

\footnotetext{
This work was supported by institutional funds of the Department of Cardiac, Thoracic, and Vascular Surgery, MediClin Heart Center Lahr, Germany, and the Department of Cardiovascular Surgery and Research Group for Experimental Surgery, Heinrich Heine University, Medical Faculty, Duesseldorf, Germany. Received for publication Sept 18, 2017; revisions received Feb 9, 2018; accepted for publication Feb 25, 2018; available ahead of print May 31, 2018.

Address for reprints: Alexander Albert, MD, PhD, Department of Cardiovascular Surgery, Heinrich Heine University, Medical Faculty, Moorenstr 5, 40225 Duesseldorf, Germany (E-mail: alexander.albert@med.uni-duesseldorf.de). $0022-5223 / \$ 36.00$

Copyright (C) 2018 by The American Association for Thoracic Surgery https://doi.org/10.1016/j.jtcvs.2018.02.111
} 


\section{Abbreviations and Acronyms \\ anOPCAB = anaortic (aortic no-touch) off-pump coronary artery bypass grafting \\ $\mathrm{CABG}=$ coronary artery bypass grafting \\ $\mathrm{CI}=$ confidence interval \\ $\mathrm{CPB}=$ cardiopulmonary bypass \\ OPCAB = off-pump coronary artery bypass grafting \\ $\mathrm{OR}=$ odds ratio}

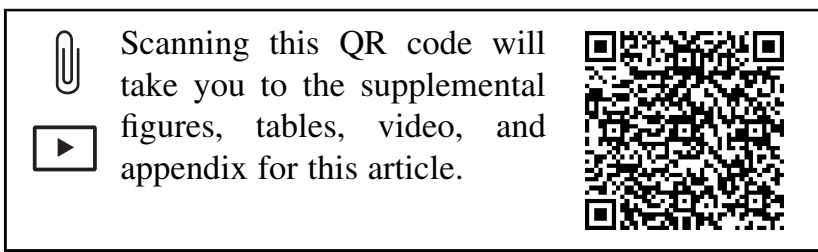

Postoperative strokes occur with an incidence of $1.4 \%$ to $3.8 \%$ after coronary artery bypass grafting $(\mathrm{CABG}) .{ }^{1}$ The risk of postoperative stroke ranks highest immediately after the surgery, and decreases over time according to the individual risk profile. Approximately half of the stroke patients present with neurological deficits directly after emergence from anesthesia. ${ }^{2}$

Established risk factors of stroke comprise atherosclerotic manifestations, such as peripheral vascular disease, carotid artery disease or aortic sclerosis, cardiac low-output syndrome, and perioperative atrial fibrillation. Besides prophylactic measures aimed at the maintenance of hemodynamic and metabolic stability during the perioperative period, the avoidance of cardiopulmonary bypass (CPB) has been hypothesized to play a major role in stroke prevention. ${ }^{1,3}$ Conventional off-pump CABG (OPCAB) trials have so far failed to show reduced stroke rates compared with $\mathrm{CPB}-\mathrm{CABG} .^{3-6}$

Because atherosclerosis is a major risk factor for stroke, surgical techniques have been developed that minimize ("clampless technique") ${ }^{7}$ or completely avoid ("anaortic/aortic no-touch technique") aortic manipulation. The clampless technique includes beating heart revascularization on $\mathrm{CPB}$ as well as OPCAB with proximal aortic anastomoses, and thus avoids aortic cross-clamping and cardioplegic arrest, but yet causes relevant aortic manipulation. According to previous studies, the risk of stroke seemed to be directly related to the extent of aortic manipulation. ${ }^{7,8}$ Since the first report on anaortic OPCAB (anOPCAB), ${ }^{9} 20$ studies including cohorts of 50 to 1500 patients have been published, none of which was a prospective randomized trial. Meta-analyses have revealed a $60 \%$ to $78 \%$ reduction of postoperative stroke using anOPCAB compared with $\mathrm{CPB}$ patients. ${ }^{7,8}$
Besides a general reduction of the overall stroke risk, anOPCAB might particularly have a beneficial effect on the occurrence of early versus delayed strokes. Hogue et al have described different risk factors for early versus delayed strokes, such as duration of extracorporeal circulation and aortic sclerosis for early strokes, and diabetes, atrial fibrillation, and cardiac low-output syndrome for delayed strokes. ${ }^{2}$ These data imply 2 different pathophysiological mechanisms for CABG-associated stroke: aorta-originated embolism by surgical manipulation is likely the major cause for early strokes, whereas cardiac thromboembolism by atrial fibrillation, as well as hemodynamic and coagulatory cofactors, might be the predominant cause for delayed strokes. Considering the current evidence on underlying mechanisms and the observed timeline for stroke after surgical coronary revascularization, we analyzed the outcome of 13,279 patients who underwent anOPCAB or CPB-CABG with a particular focus on the incidence and time point of stroke.

\section{METHODS \\ Patients}

The patient population consisted of 15,042 consecutive patients who underwent isolated CABG from 1998 to 2014 at the Heart Center Lahr/Baden, Germany. Whereas until 2004, CABG surgeries were performed as CPB procedures or "side-clamp" OPCAB, we started to use the anOPCAB technique on a routine basis from 2005 onward. After exclusion of all patients with cardiogenic shock $(n=897)$ and "side-clamp" OPCAB ( $\mathrm{n}=920), 13,279$ patients (4485 with anOPCAB; 8794 with on-pump $\mathrm{CABG}$ ) were included in the main analyses. Additionally, subgroup analyses on "side-clamp" OPCAB versus on-pump CABG in 1998 to 2004 and on anOPCAB versus on-pump CABG in 2005 to 2014 were conducted.

The study was approved by the local ethics committee and complied with the Declaration of Helsinki. Patient care, at the operative and the postoperative stages, followed the standardized guidelines of the hospital

\section{Surgical Technique}

Presuming manipulation of the aorta would represent the key factor leading to surgical strokes, the anOPCAB technique was adopted from a specialized center during a 12 -month training $\operatorname{program}^{10}$ and was rapidly established as routine procedure in our hospital. ${ }^{11}$ Whereas in the initial phase, only a limited number of specialized surgeons applied the anOPCAB technique, subsequently, more surgeons were trained, resulting in a final number of 18 consultants and residents applying this technique, and an anOPCAB rate of more than $80 \%$ of all CABG cases. After having been trained, each surgeon has used anOPCAB as a first choice procedure for myocardial revascularization.

AnOPCAB was performed in a standardized fashion according to the techniques described previously. ${ }^{12}$ Automated ST-segment analysis, central venous pressure, as well as pulmonary artery pressure readings, and intermittent cardiac output measurements (Swan-Ganz catheter) were used for hemodynamic monitoring. The routine use of a pericardial sling and an apical suction device for positioning, a blowing device for improved vision, and intracoronary shunts for adequate myocardial perfusion during generation of the anastomoses played a major role. In most cases, both internal thoracic arteries were harvested in a skeletonized manner, and left internal thoracic arteries were implanted as in situ grafts, whereas right internal thoracic arteries were used as either in situ or composite grafts Additionally, radial arteries and saphenous veins served as composite grafts as well. All arterial and venous composite grafts were implanted creating 
proximal T-anastomoses with the left internal thoracic artery. The graft choice was made according to the surgeon's decision, respecting the individual level of experience and patient-related factors such as comorbidities, risk factors for sternal wound infection, and coronary anatomy.

The on-pump approach for CABG included blood cardioplegia and the single-clamp technique. Bypass flow measurements were routinely used for all $\mathrm{CABG}$ procedures. Following the intention-to-treat principle, patients with intraoperative conversion from anOPCAB to OPCAB or to $\mathrm{CPB}$ (33 of 4485 anOPCAB patients $=0.74 \%$ ) were assigned to the anOPCAB group. In Video 1, the anOPCAB technique as well as the key results of the present study are shown.

\section{Data Acquisition}

All intrahospital parameters were collected from the data acquisition and storage system of the hospital, including the previously published Data Mart system. $^{13}$ Mortality and stroke within 30 days after CABG were meticulously recorded with a completeness of $99.5 \%$ applying a specific procedure, which we performed routinely since 1996, and which is on the basis of questionnaires and phone calls to the patients after discharge.

\section{Stroke Diagnosis}

Stroke was defined according to the World Health Organization definition as "rapidly developing clinical signs of focal (or global) disturbance of cerebral function, with symptoms lasting 24 hours or longer or leading to death, with no apparent cause other than of vascular origin." In this context, transient ischemic events were excluded. The temporal onset of the deficits was classified according to the definitions of Hogue et al as either "an early stroke, if the neurological deficit was present after emergence from anesthesia," or "a delayed stroke, if the patient developed the neurological deficit after first awaking from surgery without a neurological deficit." ${ }^{2}$ For assessment of the stroke severity and analysis of the clinical effects, minor strokes with reversible symptoms and major strokes (Rankin class $\geq 2$ ) with persistent neurological impairment after discharge were differentiated. In case of any neurological impairment, a neurologist was consulted for further diagnosis and therapy. According to the recommendation of the neurologist, in $80 \%$ of the patients, clinical assessment was further confirmed using cranial computed tomography scanning. The primary neurologist was the same physician over the entire study period.

\section{Statistics}

Descriptive statistics are presented as mean value \pm standard error of the mean for all continuous variables with Gaussian distribution. For direct comparisons of groups with continuous variables, 2-tailed Student $t$ tests or Mann-Whitney $U$ tests were performed, as indicated. Regarding categorial variables, $\chi^{2}$ tests were conducted for direct group comparisons. For continuous variables, the $95 \%$ confidence intervals (CIs) of the mean differences are presented, whereas for categorial variables, the $95 \%$ CIs of the ratio of proportions (no/yes) is given. Because of the large patient cohorts compared, the effect size of the preoperative characteristics was measured using Cramer $\mathrm{V}$ tests. Stepwise backward logistic regression analyses (Wald) were conducted to select the independent variables that could predict the occurrence of (post)operative strokes. Additionally, multivariate multinomial regression analyses were performed to detect predictors for the outcomes stroke, early stroke, and delayed stroke, with the no-stroke group serving as reference. Albeit the occurrence of postoperative stroke is a time-related event, it was analyzed as a discrete event, because the time points of disease initiation and diagnosis often do not match, particularly in case of delayed awakening due to stroke. Significance was assumed if $P$ values were $<.05$. Data analysis was conducted with SPSS Statistics for Windows (v23; IBM Corp, Armonk, NY).

In principal, we consider traditional risk adjustment using multivariate analyses as a more appropriate concept for this study compared with propensity score-based methods. However, to clear out any potential

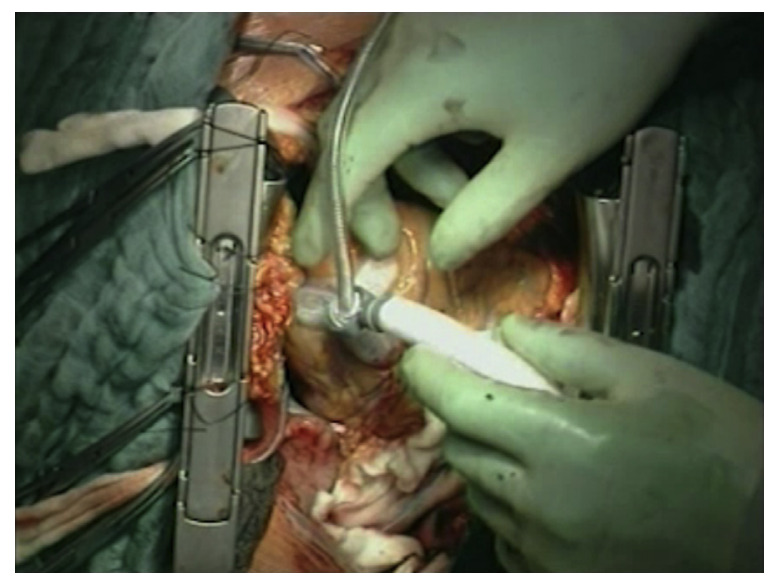

VIDEO 1. Surgical technique of anaortic OPCAB and key comments to the findings of the present study. Video available at: https://www.jtcvs. org/article/S0022-5223(18)30942-5/fulltext.

method-related validity doubts, we also provide 1:1 propensity scorebased (nearest neighbor method; caliper 0.15) analyses in Appendix E1.

\section{RESULTS \\ Pre- and Intraoperative Characteristics in anOPCAB Versus On-Pump CABG Patients}

A comparison of the preoperative variables showed that the conversion from on-pump CABG to anOPCAB as routine procedure comprised the whole risk spectrum of patients (Figure 1). Neither for the percentage of emergency cases nor for classical stroke risk factors, such as atrial fibrillation, preoperative stroke, carotid artery disease, or peripheral vascular disease, systematic differences were detected. The on-pump group contained slightly more patients with severely impaired left ventricular function and acute coronary syndrome.

Analyses of the intraoperative variables revealed a significantly higher percentage of arterial revascularization using the right internal thoracic arteries and radial arteries in the anOPCAB group, whereas the total number of peripheral anastomoses was only slightly decreased. Despite the technically more demanding procedure, using mostly both internal thoracic arteries, the surgery times were shorter with anOPCAB (Table 1).

\section{Postoperative Outcome Characteristics in anOPCAB Versus On-Pump CABG Patients}

$A n O P C A B$ resulted in a significant reduction of the postoperative overall stroke risk $(0.49 \% ; 95 \% \mathrm{CI}$, $0.29 \%-0.69 \%$ for anOPCAB patients vs $1.31 \% ; 95 \% \mathrm{CI}$, $1.07 \%-1.55 \%$ in $\mathrm{CPB}$ patients; $P<.0001)$. As a consequence, the overall stroke rate in the time interval from 2005 to $2014(0.64 \%)$ was significantly decreased compared with the time interval from 1998 to 2004 $(1.40 \% ; P<.0001)$. Direct group comparisons between anOPCAB and on-pump CABG patients were conducted 


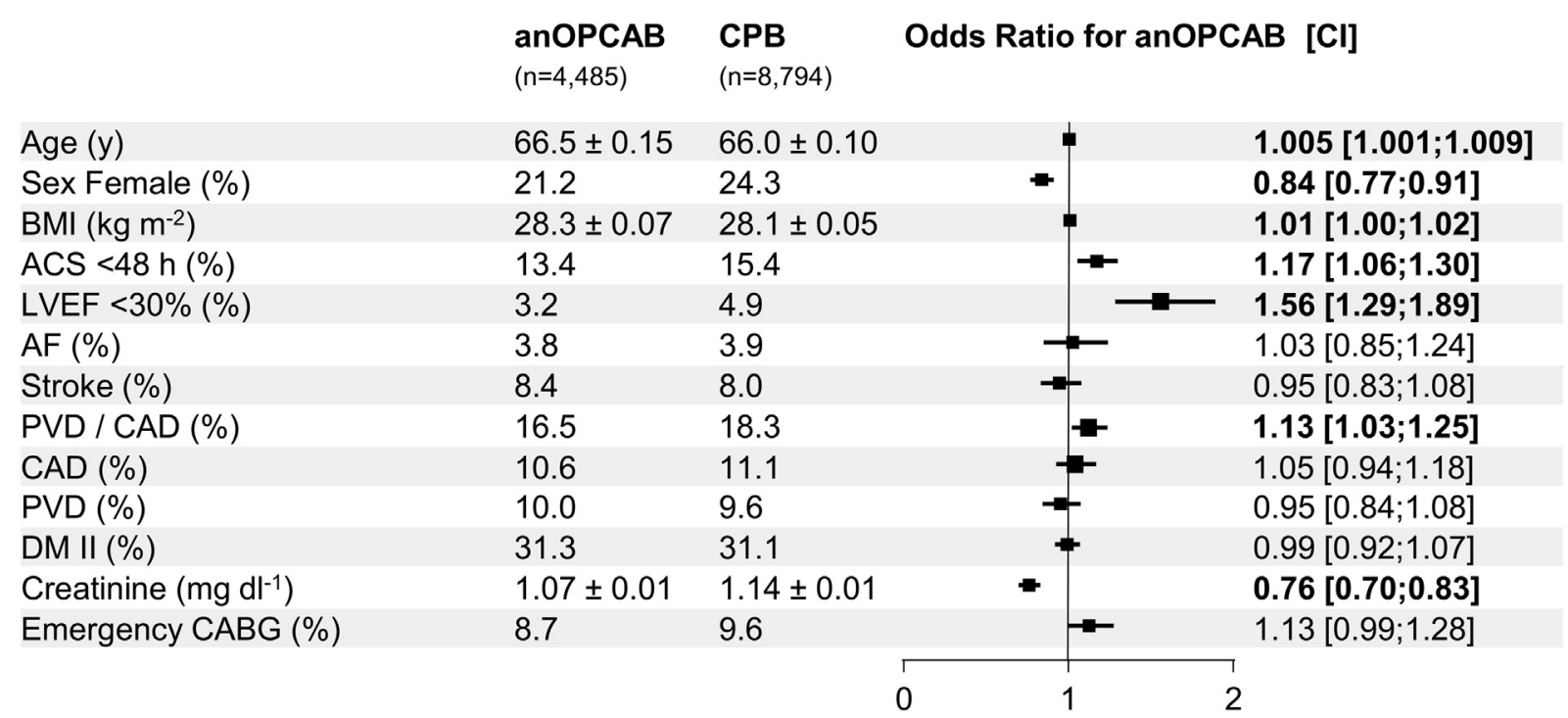

FIGURE 1. Baseline characteristics of patients undergoing anOPCAB versus on-pump CABG. Results are on the basis of univariate logistic regression with level of significance of .05. For continuous variables, the CI for the mean differences are given; for categorial variables, the CI for the ratio of proportions (no/yes) is given. anOPCAB, Anaortic off-pump coronary artery bypass grafting; $C P B$, cardiopulmonary bypass; $C I$, confidence interval; $B M I$, body mass index; $A C S$, acute coronary syndrome; $L V E F$, left ventricular ejection fraction; $A F$, atrial fibrillation; $P V D$, peripheral vascular disease; $C A D$, carotid artery disease; $D M I I$, diabetes mellitus type II; $C A B G$, coronary artery bypass grafting.

to analyze the postoperative clinical morbidity and mortality dependent on the surgical technique (Table 2). The occurrence of cardiopulmonary resuscitation, rethoracotomy, or reintubation was significantly lower, whereas the creatinine levels were higher after anOPCAB. The 30-day mortality was equal between the 2 groups.

\section{Stroke Rate and Postoperative Time Interval After Introduction of anOPCAB}

After introduction of the anOPCAB technique in 2005, its adoption developed rapidly in our center, covering $>80 \%$ of all treated CABG patients. In the year of introduction of anOPCAB, the overall institutional stroke rate in all $\mathrm{CABG}$ patients decreased below $1 \%$ for the first time, resulting in a significant reduction during the time interval from 2005 to 2014 compared with the time interval from 1998 to 2004 ( $P<.0001$; Figure 2). Even more noteworthy, the occurrence of early strokes has been minimized when using the anaortic technique. Strikingly, these reductions in stroke incidence occurred immediately after introduction of the new technique and were sustained.

The decrease in stroke risk after adoption of anOPCAB was additionally shown using linear-by-linear association tests revealing a significant result over the whole study period $(P=.0004$ in 1998-2014), whereas the data for the "pre-anOPCAB era" $(P=.6812$ in 1998-2004) and the "anOPCAB era" ( $P=.8671$ in $2005-2014)$ did not show a significant reduction of the stroke rate so that a timerelated stroke risk reduction independently of the adoption of anOPCAB could be ruled out. Similar results were obtained when considering the time point (early or delayed) of stroke occurrence $(P=.3424$ in $1998-2004$ and $P=.4764$ in 2005-2014).

Among the patients with operative and postoperative strokes, on-pump patients suffered from significantly earlier strokes compared with anOPCAB patients (Figure 3). The

TABLE 1. Intraoperative variables of patients undergoing anOPCAB versus on-pump CABG

\begin{tabular}{|c|c|c|c|c|}
\hline Variable & $\operatorname{anOPCAB}(n=4485)$ & CPB $(n=8794)$ & OR (CI) & $P$ value \\
\hline Surgery time, minutes & $188.4 \pm 0.71$ & $198.1 \pm 0.53$ & - & $<.0001$ \\
\hline Graft number & $2.0 \pm 0.01$ & $2.6 \pm 0.01$ & - & $<.0001$ \\
\hline Peripheral anastomoses, $\mathrm{n}$ & $2.8 \pm 0.01$ & $3.1 \pm 0.01$ & - & $<.0001$ \\
\hline RITA graft, $\mathrm{n}(\%)$ & $3091(68.9)$ & $1177(13.4)$ & $14.4(13.1-15.7)$ & $<.0001$ \\
\hline Radial artery graft, $\mathrm{n}(\%)$ & $167(3.7)$ & $37(0.42)$ & $9.2(6.4-13.1)$ & $<.0001$ \\
\hline Saphenous vein graft, $\mathrm{n}(\%)$ & $1088(24.3)$ & $7215(82.0)$ & $0.07(0.06-0.08)$ & $<.0001$ \\
\hline
\end{tabular}

For categorial variables, the CI for the ratio of proportions (no/yes) is given. $P$ values indicating statistically significant differences are in bold. anOPCAB, Anaortic off-pump coronary artery bypass grafting; $C P B$, cardiopulmonary bypass; $O R$, odds ratio; $C I$, confidence interval; RITA, right internal thoracic artery graft. 
TABLE 2. Outcome of patients undergoing anOPCAB versus on-pump CABG

\begin{tabular}{|c|c|c|c|c|}
\hline Variable & $\operatorname{anOPCAB}(n=4485)$ & CPB $(n=8794)$ & OR (CI) & $P$ value \\
\hline Stroke & $22(0.49)$ & $115(1.3)$ & $0.37(0.24-0.59)$ & $<.0001$ \\
\hline Major stroke & $13(0.29)$ & $93(1.1)$ & $0.27(0.15-0.49)$ & $<.0001$ \\
\hline Early stroke & $4(0.09)$ & $73(0.83)$ & $0.11(0.04-0.29)$ & $<.0001$ \\
\hline Major early stroke & $3(0.07)$ & $64(0.73)$ & $0.09(0.03-0.29)$ & $<.0001$ \\
\hline Delayed stroke & $18(0.40)$ & $42(0.48)$ & $0.83(0.48-1.45)$ & .5181 \\
\hline Major delayed stroke & $10(0.22)$ & $29(0.33)$ & $0.67(0.33-1.38)$ & .312 \\
\hline ACS & $111(2.5)$ & $173(2.0)$ & $1.27(0.99-1.61)$ & .0558 \\
\hline CPR & $52(1.2)$ & $162(1.8)$ & $0.63(0.46-0.86)$ & .0031 \\
\hline Rethoracotomy & $75(1.7)$ & $195(2.2)$ & $0.75(0.57-0.98)$ & .0353 \\
\hline Reintubation & $85(1.9)$ & $228(2.6)$ & $0.73(0.56-0.93)$ & .0122 \\
\hline Creatinine, $\mathrm{mg} / \mathrm{dL}$ & $1.24 \pm 0.02$ & $1.20 \pm 0.01$ & - & .0214 \\
\hline CVVHDF & $161(3.6)$ & $328(3.7)$ & $0.96(0.79-1.17)$ & .6852 \\
\hline 30-d mortality & $55(1.2)$ & $143(1.6)$ & $0.75(0.55-1.03)$ & .0722 \\
\hline
\end{tabular}

Data are presented as n (\%) except where otherwise noted. $P$ values indicating statistically significant differences are in bold. anOPCAB, Anaortic off-pump coronary artery bypass grafting; $C P B$, cardiopulmonary bypass; $O R$, odds ratio; $C I$, confidence interval; $A C S$, acute coronary syndrome; $C P R$, cardiopulmonary resuscitation; $C V V H D F$, chronic veno-venous hemodiafiltration.

postoperative interval until the occurrence of stroke was $68.1 \pm 9.9$ hours in anOPCAB patients and $50.6 \pm 4.8$ hours in on-pump control patients $(P=.0285)$.

When dividing strokes into early and delayed strokes, anOPCAB was shown to significantly reduce the probability that a stroke occurs as early stroke $(18.2 \%$ vs $63.5 \%$ in CPB patients with $P<.0001$ and odds ratio [OR], 7.8; 95\% CI, 2.48-24.7). The early stroke rate after anOPCAB amounted to $0.09 \%$ (95\% CI, 0.00-0.18\%) versus $0.83 \%(95 \% \mathrm{CI}, 0.64 \%-1.02 \%)$ in $\mathrm{CPB}$ patients $(P<.0001)$, whereas delayed strokes were not significantly reduced $(0.40 \%$ [95\% CI, $0.22 \%-0.59 \%$ ] vs $0.48 \%$ [95\% CI, $0.33 \%-0.62 \%])$ in CPB patients $(P=.5355)$.

\section{Risk Factors of Stroke and Early/Delayed Stroke}

To determine the effect of preoperative risk factors on the postoperative stroke incidence, and on early as well as delayed strokes in particular, univariate statistical testing was conducted. The results are shown in Table 3.

Multivariate logistic regression analyses were performed to test potential preoperative risk factors of strokes in general, and early as well as delayed strokes in particular.

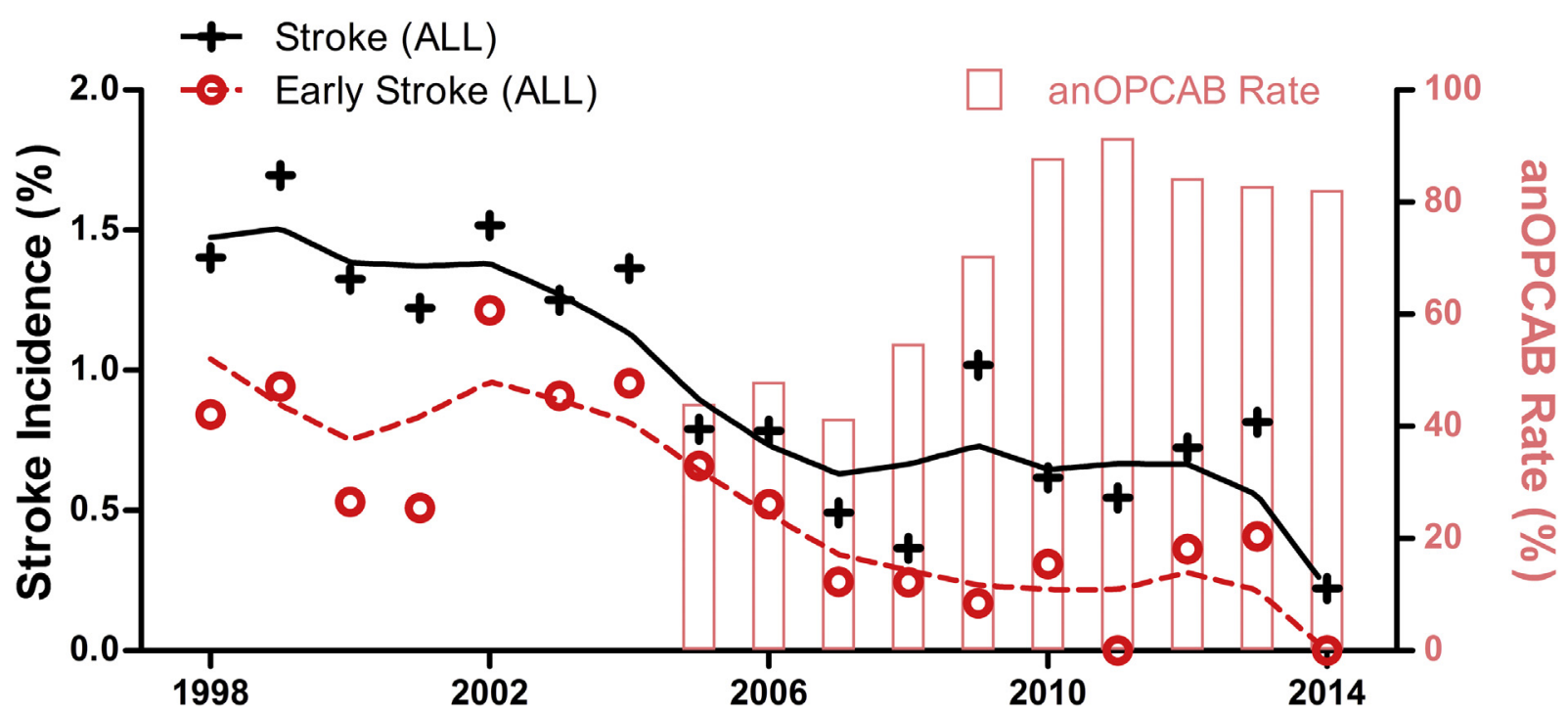

FIGURE 2. Annual stroke and early stroke rates. Reduction of the overall stroke rate (black crosses; $P<.0001)$ and the early stroke rate (red rings) in all patients after the adoption of anOPCAB (red bars, right y-axis) starting in 2005. Curve fitting was performed according to the nonparametric Locally Weighted Scatterplot Smoothing method. anOPCAB, Anaortic off-pump coronary artery bypass grafting. 


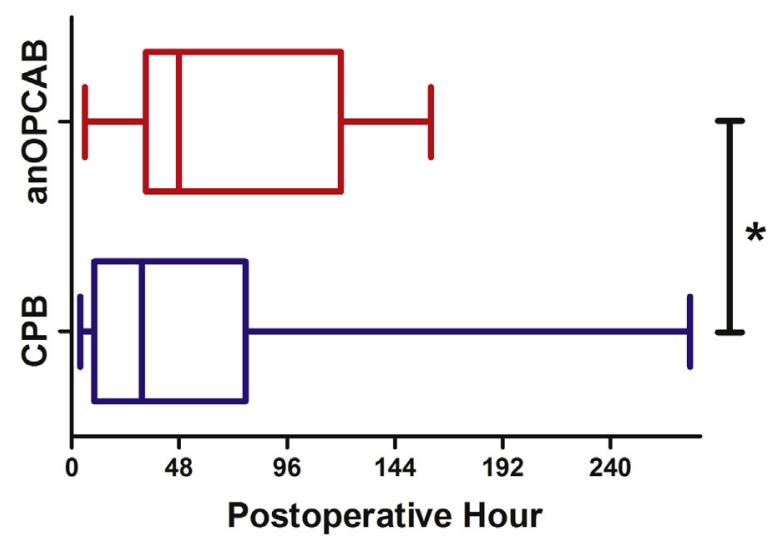

FIGURE 3. Time interval between coronary artery bypass grafting and the occurrence of stroke. Significantly earlier occurrence of strokes after on-pump coronary artery bypass grafting versus anOPCAB. Box plot whiskers show minimum and maximum values; $* P<.05$. anOPCAB, Anaortic off-pump coronary artery bypass grafting; $C P B$, cardiopulmonary bypass.

High goodness-of-fit was confirmed using the HosmerLemeshow test for the regression targeting strokes in general $(P=.5793)$ and the deviance test for the regression targeting the time point of stroke $(P=1.000)$. In Figure 4, forest plots indicate that anOPCAB reduced the overall stroke incidence (OR, 0.33; 95\% CI, 0.21-0.53; $P<.0001)$ by reduction of early strokes (OR, 0.09; $95 \%$ CI, 0.03-0.26; $P<.0001$ ), whereas delayed strokes occurred independently of the surgical technique (OR, $0.76 ; 95 \% \mathrm{CI}$, 0.43-1.33; $P=.3352$ ). Established risk factors of (post) operative stroke (preoperative stroke, atrial fibrillation, peripheral vascular disease, age) were confirmed in our patient cohorts. Remarkably, the risk factors of early versus delayed strokes were different. Whereas preoperative atrial fibrillation was a risk factor specifically for delayed strokes, peripheral and carotid artery disease were risk factors specifically for early strokes.

To account for potential time effects over the long study period, such as general improvement of patient care, additional subgroup analyses were conducted comparing "side-clamp" OPCAB versus on-pump CABG in 1998 to 2004 ("pre-anOPCAB era") and anOPCAB versus on-pump CABG in 2005 to 2014. These analyses revealed that "side-clamp" OPCAB does not influence the risk of strokes in general, early or late strokes (Figure E1), whereas anOPCAB was confirmed to decrease the risk of strokes in general and particularly early strokes, but not delayed strokes (Figure E2).

Four of 4485 anOPCAB patients presented with an early stroke. Thorough review of these cases showed enhanced stroke risk profiles due to factors such as polycythemia vera, preoperative stroke, carotid artery disease, and atrial fibrillation, but particularly intraoperative episodes of unusually low systemic blood pressure (Table 4).

\section{Severity of Stroke and Relation to Mortality}

Among all stroke patients, major strokes presented more likely than minor strokes in the CPB group $(81.6 \%$ major strokes) compared with the anOPCAB group $(59.1 \%$ major strokes) with $P=.0199$. In the CPB group, stroke was associated with 30-day mortality. Stroke patients had a mortality risk of $7.0 \%$, whereas only $1.6 \%$ mortality was observed in nonstroke patients at 30 days $(P<.0001)$. In

TABLE 3. Occurrence of stroke and early versus delayed stroke in dependency on preoperative risk factors and the surgical technique

\begin{tabular}{|c|c|c|c|c|c|c|}
\hline Characteristic & $\begin{array}{c}\text { No stroke } \\
(n=13,142)\end{array}$ & $\begin{array}{c}\text { Stroke } \\
(\mathbf{n}=137)\end{array}$ & $P$ value & $\begin{array}{c}\text { Early stroke } \\
(\mathbf{n}=77)\end{array}$ & $\begin{array}{l}\text { Delayed stroke } \\
\quad(\mathbf{n}=60)\end{array}$ & $P$ value \\
\hline Age, y & $66.1 \pm 0.08$ & $70.3 \pm 0.63$ & $<.001$ & $70.7 \pm 0.79$ & $69.8 \pm 1.03$ & .4691 \\
\hline Female sex, $\%$ & 23.2 & 29.9 & .0631 & 26.0 & 35.0 & .2524 \\
\hline BMI & $28.2 \pm 0.04$ & $28.0 \pm 0.34$ & .7599 & $28.1 \pm 0.49$ & $28.0 \pm 0.48$ & .8390 \\
\hline ACS $<48 \mathrm{~h}, \%$ & 14.7 & 21.2 & .0328 & 50.6 & 31.7 & .0257 \\
\hline LVEF $<30 \%, \%$ & 4.3 & 4.4 & .9562 & 3.9 & 5.0 & .7541 \\
\hline $\mathrm{AF}, \%$ & 3.7 & 14.6 & $<.0001$ & 6.5 & 25.0 & .0023 \\
\hline Stroke, \% & 7.9 & 29.2 & $<.0001$ & 32.5 & 25.0 & .3402 \\
\hline CAD/PVD (\%) & 17.5 & 43.1 & $<.0001$ & 49.4 & 35.0 & .0924 \\
\hline $\mathrm{CAD}, \%$ & 10.8 & 25.5 & $<.0001$ & 30.0 & 20.0 & .1888 \\
\hline PVD, $\%$ & 9.5 & 27.0 & $<.0001$ & 26.0 & 28.3 & .7576 \\
\hline DM II, \% & 31.1 & 39.4 & .0362 & 35.1 & 45.0 & .2377 \\
\hline Creatinine, $\mathrm{mg} / \mathrm{dL}$ & $1.1 \pm 0.01$ & $1.3 \pm 0.07$ & .0159 & $1.39 \pm 0.12$ & $1.18 \pm 0.06$ & .1674 \\
\hline Emergency CABG, \% & 9.3 & 13.1 & .1200 & 14.3 & 11.7 & .6526 \\
\hline anOPCAB, $\%$ & 34.0 & 16.1 & $<.001$ & 5.2 & 30.0 & $<.001$ \\
\hline
\end{tabular}

$P$ values indicating statistically significant differences are in bold. $B M I$, Body mass index; $A C S$, acute coronary syndrome; $L V E F$, left ventricular ejection fraction; $A F$, atrial fibrillation; $C A D$, carotid artery disease; $P V D$, peripheral vascular disease; $D M I I$, diabetes mellitus type II; $C A B G$, coronary artery bypass grafting; anOPCAB, anaortic offpump coronary artery bypass grafting. 


\section{Stroke}

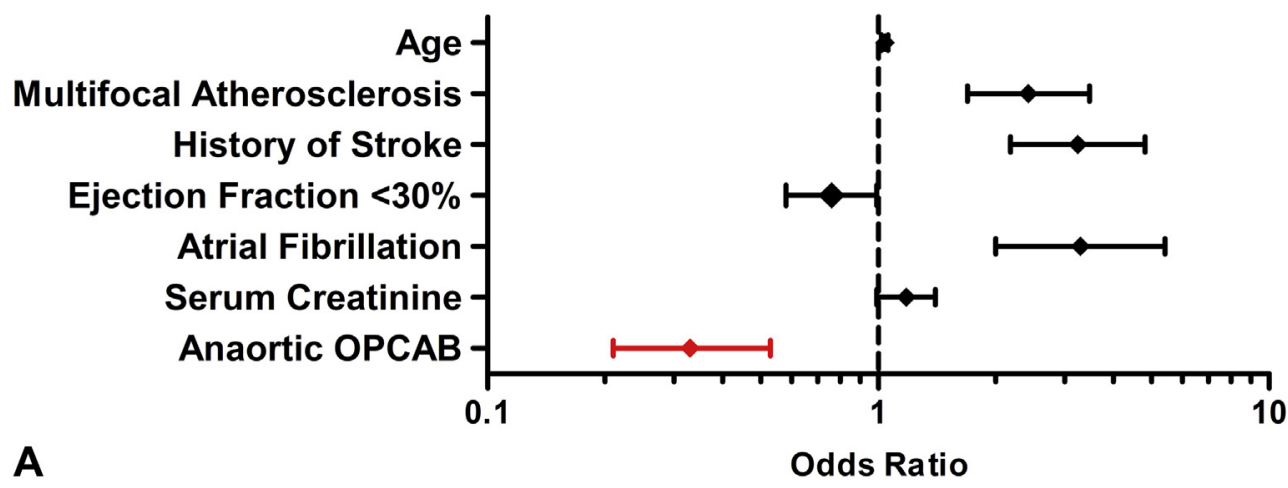

\section{Early Stroke}

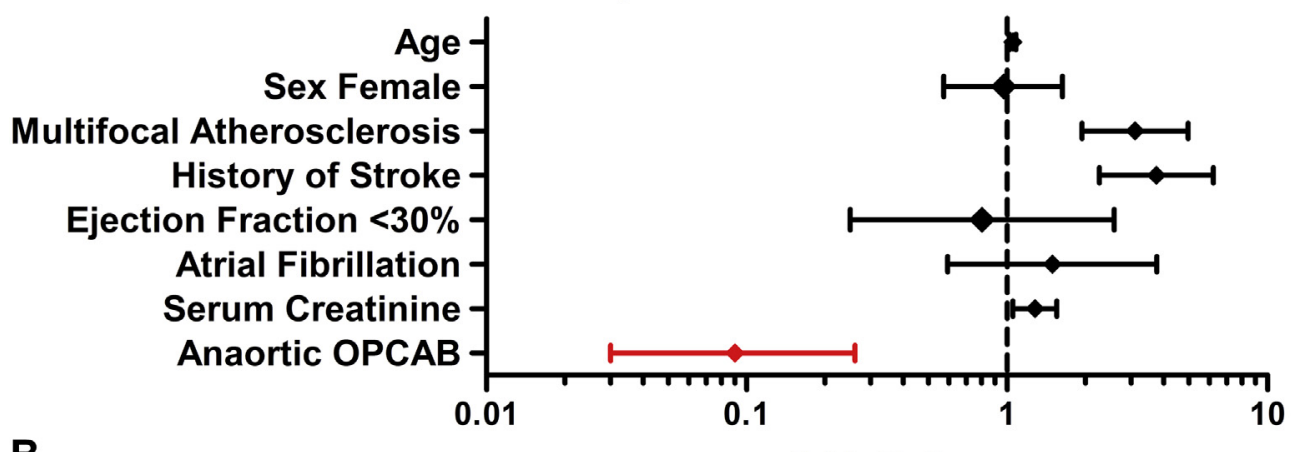

B

Odds Ratio

\section{Delayed Stroke}

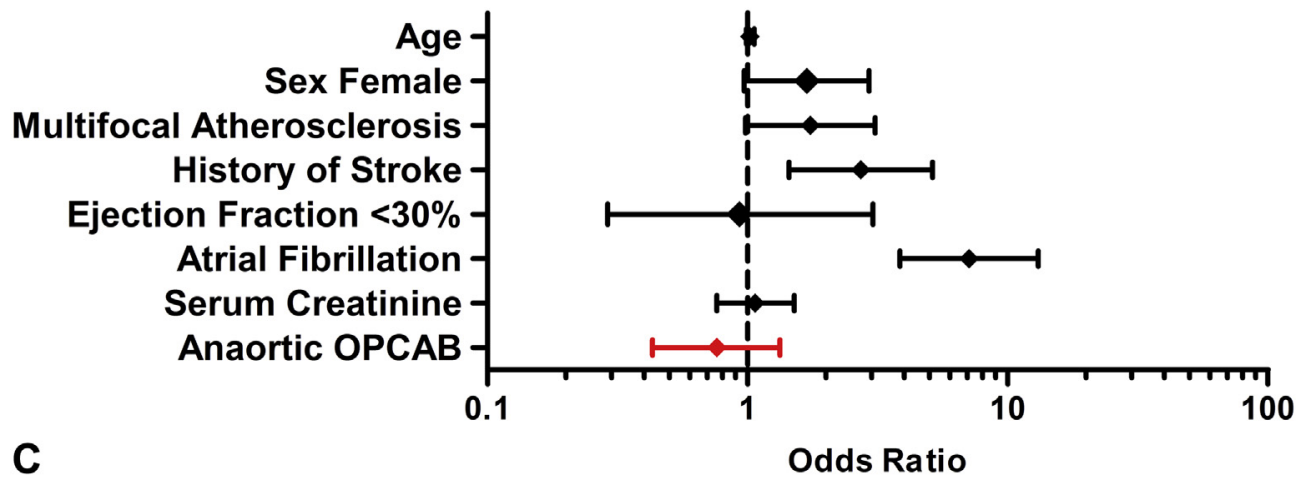

FIGURE 4. Risk factors for (A) stroke, (B) early stroke, and (C) delayed stroke. Prevention of early but not delayed strokes by anaortic OPCAB. Confirmation of well described stroke risk factors. $O P C A B$, Off-pump coronary artery bypass grafting.

the anOPCAB group, there was no statistically significant difference regarding 30-day mortality in the subgroups of patients with versus without stroke, respectively (0 vs $1.2 \%$ with $P=.6003)$. Considering patients from both groups, stroke increased the mortality risk $(5.8 \%$ vs $1.4 \%$ with $P<.0001)$.

\section{Propensity Score-Based Case Control Analysis}

To enable alternatives for estimation of the internal validity of the study, an additional propensity score matching was conducted, the results of which are presented in Appendix E1. Most importantly, it was confirmed that anOPCAB significantly reduces the overall stroke as well 
TABLE 4. Patients with early stroke after anOPCAB (4 of 4485)

\begin{tabular}{|c|c|c|c|c|c|c|c|}
\hline Number & Sex & Neurological deficit & CT imaging & $\begin{array}{c}\text { CAD } \\
\text { (preoperative) }\end{array}$ & $\begin{array}{c}\text { PVD } \\
\text { (preoperative) }\end{array}$ & $\begin{array}{c}\text { AF } \\
\text { (postoperative new) }\end{array}$ & Remarks \\
\hline 1 & $\mathrm{~F}$ & $\begin{array}{l}\text { Left hemiparesis, } \\
\text { left hemianopsia }\end{array}$ & $\begin{array}{l}\text { Right middle cerebral } \\
\text { artery embolism }\end{array}$ & No & No & Yes & Low SBP intraoperatively \\
\hline 2 & M & Left hemiparesis & No signs & Yes & Yes & No & $\begin{array}{l}\text { Polycythemia vera, } \\
\text { escalated hemotherapy } \\
\text { intraoperatively, } \\
\text { low SBP intraoperatively }\end{array}$ \\
\hline 3 & M & $\begin{array}{l}\text { Left hemiparesis, } \\
\text { somnolence }\end{array}$ & No signs & No & No & Yes & $\begin{array}{l}\text { Disseminated cerebral } \\
\text { embolism preoperatively, } \\
\text { liver transplantation }\end{array}$ \\
\hline 4 & M & $\begin{array}{l}\text { Left hemiplegia, } \\
\text { dysarthria }\end{array}$ & $\begin{array}{l}\text { Right precentral } \\
\text { embolism }\end{array}$ & Yes & Yes & Yes & $\begin{array}{l}\text { Cerebral embolism } \\
\text { preoperatively, low SBP } \\
\text { intraoperatively }\end{array}$ \\
\hline
\end{tabular}

$C T$, Computed tomography; $C A D$, carotid artery disease; $P V D$, peripheral vascular disease; $A F$, atrial fibrillation; $F$, female; $S B P$, systemic blood pressure; $M$, male.

as the early stroke rate, whereas the delayed stroke risk was not influenced. In particular, the early stroke risk in anOP$\mathrm{CAB}$ patients amounted to $<0.1 \%$, compared with a 10 fold higher risk in $\mathrm{CPB}$ patients.

\section{DISCUSSION}

The present article reports clinical results 10 years after introduction of anOPCAB for myocardial revascularization at a single institution. Herein, the anOPCAB technique has been used as first choice procedure for most patients covering the whole neurological as well as cardiovascular risk spectrum of unselected CABG patients, counteracting the potential bias of study participation as well as Berkson's selection bias. Because of the so far highest published number of anOPCAB cases, differentiated examination of the incidence and time-related occurrence of the rare event of stroke was realized, thereby also allowing for high reliability and validity of the study results. Particularly, to the best of the authors' knowledge, we are the first to report that the anOPCAB technique influences the stroke incidence after coronary surgery in a time-dependent manner. The understanding of this temporal dependence is an important step in stroke prevention and individual therapy tailoring for patients suffering from coronary artery disease.

\section{Early Strokes After CABG: A Solved Issue}

Since the 1990s, a prospective database, including meticulous neurological documentation, has been systematically recorded in our department to identify and control risk factors of postoperative stroke, such as the shape of the aortic cannula in on-pump patients, high preoperative leucocyte counts, and undiagnosed diabetes. ${ }^{14-16}$ In the following years, the overall incidence of stroke has amounted to approximately $1.4 \%$. To control the presumable key factor of surgical strokes (ie, manipulation of the aorta), the anOPCAB technique was implemented as a routine procedure at the institutional level.

As a major result, we show in a large series of consecutive anOPCAB patients, that CABG can be performed with a stable general stroke rate of $0.49 \%(95 \%$ CI, $0.29 \%$ $0.69 \%$ ). Furthermore, we show that after adoption of anOPCAB, the overall stroke rate for all CABG patients at a single center can be significantly reduced. In particular, our large cohort study assures that anOPCAB decreases the risk of early strokes to $<0.09 \%$ ( $95 \% \mathrm{CI}, 0.00-0.18 \%$ ).

The differentiation of perioperative strokes as early versus delayed strokes is of utmost interest, because the pathophysiological mechanisms are supposed to be rather different. Among all published studies, only 3 series have differentiated early postoperative and delayed strokes, ${ }^{17-19}$ and reported early stroke incidences of $0^{18,19}$ and $0.1 \%{ }^{17}$ The latter study in 1553 patients revealed aortic manipulation as risk factor for strokes in general, for early strokes with a high OR of 7.2, but also for delayed strokes, although to a smaller extent. The fact that anOPCAB in our study has specifically prevented early but not delayed strokes, confirms the hypothesis that embolism from the thoracic aorta is the main cause for surgical strokes. With regard to this, 3 types of aortic manipulation have to be considered: (1) insertion of the arterial CPB cannula as well as the "sandblast effect" induced by the high speed jet from the cannula that is directed against the aortic wall $^{14,20}$; (2) total aortic clamping for cardioplegic arrest; and (3) partial clamping for suturing the proximal anastomoses. Studies using epiaortic ultrasound ${ }^{21}$ and transesophageal echocardiography ${ }^{22,23}$ have shown that CABG with aortic manipulation induces relevant arterial wall damage, where plaque rupture has been identified with localizations along the entire ascending aorta and the aortic arch. Furthermore, the extent of 
echocardiographically detected atherosclerosis correlates with the magnetic resonance imaging-diagnosed number of cerebral embolisms. ${ }^{24}$

Because every type of aortic manipulation has to be considered as a risk factor of stroke, conventional OPCAB with the "side clamp" approach or automatic anastomosis devices cannot reduce the occurrence of strokes, at least not to a large extent, ${ }^{25}$ which might be the underlying reason for stroke incidence between $1 \%$ and $2 \%$ reported in previous large randomized controlled trials. ${ }^{4-6}$ The multivariate subgroup analyses of the present study confirm that "side-clamp" OPCAB does not reduce the stroke risk compared with on-pump CABG.

\section{Delayed Strokes After CABG: An Unsolved Issue}

Whereas the risk of early strokes can be virtually annihilated when using the anOPCAB approach, different strategies seem to be necessary to reduce the risk of delayed strokes. Before postulating preventive strategies, the underlying pathophysiological mechanisms should be discussed.

In our study, preoperative atrial fibrillation was an independent risk factor for delayed stroke. However, recent studies could not clarify the actual role of prophylactic left atrial appendix exclusion in terms of reduction of the postoperative stroke incidence. ${ }^{26}$ Another approach to cope with atrial fibrillation is intensified anticoagulation, which might be beneficial particularly in OPCAB patients, because they have been reported to experience hypercoagulability. ${ }^{27}$ However, dual platelet inhibition with clopidogrel and acetylsalicylic acid was not superior in terms of reducing postoperative stroke, myocardial infarction, or death, whereas the frequency of major and minor bleeding was increased. ${ }^{28}$ Alternative anticoagulation strategies are under examination, such as ticagrelor in the running $\mathrm{TiCAB}$ (Ticagrelor in $\mathrm{CABG}$ ) trial (ClinicalTrials.gov identifier: NCT01755520).

Besides atrial fibrillation, cofactors for the development of strokes should be considered. Regional or global cerebral hypoperfusion might be an important cofactor, because it can impair the washout of cerebral emboli. ${ }^{29}$ In the anOPCAB patients of the present study, carotid artery disease potentially causing regional hypoperfusion was reported to be a risk factor for postoperative stroke in general as well as specifically for early stroke, as determined in univariate and multivariate analyses.

In addition to embolism, local prothrombotic activity in the cerebral arteries, interacting with perioperative hypotension and postoperative hypercoagulability, might trigger cerebral infarction. Particularly patients with preoperative history of stroke or severe multifocal atherosclerosis should be considered as susceptible to perioperative stroke by hypotension, impaired compensation of cerebral hypoperfusion, and endothelial dysfunction. ${ }^{17}$ This might explain why "history of stroke" and "peripheral vascular disease" have been reported to be independent risk factors for early as well as delayed strokes in our cohort as well as by others. ${ }^{2,30}$ Therefore, especially in high-risk patients, we regard continuous hemodynamic stability to be crucial to prevent not only early intraoperative but also delayed postoperative strokes, whereas strategies to eliminate the other previously mentioned influencing factors, such as cardiac embolism and coagulation disorders, remain to be evaluated.

\section{Implementation Strategies and Concerns}

To implement anOPCAB for daily routine, different approaches are up for discussion. In our institution, a general switch from conventional CABG to anOPCAB was aimed at, thereby covering the complete risk spectrum of patients and allowing for rapid gain in experience. The technical complexity of anOPCAB has been considered to limit the routine use of this technique, particularly for patients with impaired cardiac function or intramuscular coronary arteries, which frequently results in an imbalance of risk factors between anOPCAB and on-pump patients. In the present study, the anOPCAB technique has been established as method of choice for all CABG patients independently of the individual risk spectrum. Even emergency cases and patients with severely impaired left ventricular function or acute myocardial infarction were treated with anOPCAB, whereas patients with cardiogenic shock were a priori excluded from the study. Deviations from the routine method were partially caused by individual coronary anatomy with expected hemodynamic concerns, such as concurrent blood flow. The risk of the latter phenomenon is particularly high with arterial composite grafts, especially in the territory of the right coronary artery. ${ }^{31,32}$ Considering this, the revascularization strategy in anOPCAB has to be planned thoroughly for each individual patient.

Despite the assumed technical complexity of anOP$\mathrm{CAB}$, the surgical times were not prolonged compared with the on-pump patients. Nevertheless, complete revascularization using arterial grafts was achieved in most of all patients, which has to be considered superior to strategies including venous grafts, because arterial revascularization has been shown to decrease the long-term mortality. ${ }^{33}$

Despite avoidance of any aortic manipulation, 4 of 4485 anOPCAB patients presented with surgical strokes. In these 4 patients, intraoperative hemodynamic instability was an important characteristic. This scenario might occur in OPCAB patients particularly during revascularization of the left lateral and inferior myocardial wall, decreasing the cerebral oxygen saturation in up to $15 \%$ of the patients. ${ }^{34}$ The increase of postoperative creatinine levels in the anOPCAB group, although they presented with lower 
preoperative levels, might also be indicative for hemodynamic instability during the intraoperative course. However, according to our experience, this issue is not specific for the OPCAB technique, but can be attributed to the learning curve of the institution and the individual surgeon as well. In this context, the necessity to train and supervise all surgeons is one of the major challenges when implementing anOPCAB as routine procedure.

An alternative approach to a general switch from on-pump $\mathrm{CABG}$ to anOPCAB might be preoperative identification of patients at high stroke risk to whom the anaortic technique is selectively applied. In this scenario, screening using preoperative computed tomography and transesophageal echocardiography or intraoperative epiaortic ultrasound imaging is an important tool to select patients with relevant aortic plaques and enhanced risk of stroke (epiaortic ultrasound grade $>$ II). ${ }^{35}$ Concerns regarding the approach with specialized teams are related to the lack of institutional routine, and the necessity of switching the surgical team in case of intraoperative diagnosis of aortic atherosclerosis. Furthermore, it would have to be evaluated in a large patient series whether this approach can actually identify all risk patients and decrease the overall stroke rate to the same extent as the concept of routine usage.

\section{Limitations}

A limitation of this study is the retrospective design with CPB patients who primarily received surgery in earlier years, and OPCAB patients who predominantly received surgery in recent years. However, the rapid switch to anOPCAB as routine procedure balances typical study biases as explained previously. For patients analyzed in this study, no preoperative routine screening for atherosclerosis of the ascending aorta was conducted. However, this would probably not have affected the choice of the surgical technique, because in earlier years anOPCAB was not available, and in later years, all patients, including those with remarkable atherosclerotic profile and presumably high plaque burden received anOPCAB as the routine technique. That even high-risk patients were treated with anOPCAB resulted in a reduction of the stroke rate not only in the anOPCAB group but also in the CPB group in the time period after adoption of anOPCAB, because patients at very high risk of stroke were a priori not treated using CPB.

A neurologist was consulted only in case of any neurological impairment, whereas patients without neurological events were not routinely visited by a neurologist. Therefore, particularly minor cerebral infarction might have been underdiagnosed. To cope with this aspect, in the present analysis we included only strokes with symptoms lasting more than 24 hours, which makes it unlikely that this effect has substantially changed the findings of the study.

\section{CONCLUSIONS}

The present study has revealed 2 clearly distinctive risk factor profiles for early versus delayed strokes after coronary surgery. Implementation of the anaortic offpump technique as a routine method for all patients independently of the risk spectrum, and avoiding any manipulation of the aorta, decreased the overall stroke rate to $0.5 \%$. Particularly, the risk of early strokes was nearly annihilated, so that a preoperative patient can be assured to recover from anesthesia without focal neurological deficit with a probability of $99.9 \%$. Although the quest for prevention of early strokes seems to be solved, future research should focus on the reduction of delayed strokes.

\section{Conflict of Interest Statement}

Authors have nothing to disclose with regard to commercial support.

The authors gratefully acknowledge Kirsten Mangelsdorf and Susanne Burger (both MediClin Heart Center Lahr, Germany) for data acquisition.

\section{References}

1. Selim M. Perioperative stroke. N Engl J Med. 2007;356:706-13.

2. Hogue CW Jr, Murphy SF, Schechtman KB, Davila-Roman VG. Risk factors for early or delayed stroke after cardiac surgery. Circulation. 1999;100:642-7.

3. Deppe A-C, Arbash W, Kuhn EW, Slottosch I, Scherner M, Liakopoulos OJ, et al. Current evidence of coronary artery bypass grafting off-pump versus on-pump: a systematic review with meta-analysis of over 16900 patients investigated in randomized controlled trials. Eur J Cardiothorac Surg. 2015;49:1031-41.

4. Diegeler A, Börgermann J, Kappert U, Breuer M, Böning A, Ursulescu A, et al. Off-pump versus on-pump coronary-artery bypass grafting in elderly patients. $N$ Engl J Med. 2013;368:1189-98.

5. Shroyer AL, Grover FL, Hattler B, Collins JF, McDonald GO, Kozora E, et al. On-pump versus off-pump coronary-artery bypass surgery. $N$ Engl $\mathrm{J} \mathrm{Med}$. 2009;361:1827-37.

6. Lamy A, Devereaux PJ, Prabhakaran D, Taggart DP, Hu S, Paolasso E, et al. Off pump or on-pump coronary-artery bypass grafting at 30 days. $\mathrm{N}$ Engl $\mathrm{J} \mathrm{Med}$. 2012;366:1489-97.

7. Pawliszak W, Kowalewski M, Raffa GM, Malvindi PG, Kowalkowska ME, Szwed KA, et al. Cerebrovascular events after no-touch off-pump coronary artery bypass grafting, conventional side-clamp off-pump coronary artery bypass, and proximal anastomotic devices: a meta-analysis. J Am Heart Assoc. 2016;5: e002802.

8. Zhao DF, Edelman JJ, Seco M, Bannon PG, Wilson MK, Byrom MJ, et al. Coronary artery bypass grafting with and without manipulation of the ascending aorta: a network meta-analysis. J Am Coll Cardiol. 2017;69:924-36.

9. Lev-Ran O, Braunstein R, Sharony R, Kramer A, Paz Y, Mohr R, et al. No-touch aorta off-pump coronary surgery: the effect on stroke. J Thorac Cardiovasc Surg. 2005; 129:307-13.

10. Albert A, Peck EA, Wouters P, Van Hemelrijck J, Bert C, Sergeant P. Performance analysis of interactive multimodal CME retraining on attitude toward and application of OPCAB. J Thorac Cardiovasc Surg. 2006;131:154-62.

11. Albert A, Sergeant P, Florath I, Ismael M, Rosendahl U, Ennker JR. Process review of a departmental change from conventional coronary artery bypass grafting to totally arterial coronary artery bypass and its effects on the incidence and severity of postoperative stroke. Heart Surg Forum. 2011;14:E73-80.

12. Peck E, Sergeant P. Off-pump coronary artery bypass graft surgery. In: Yuh DD, Vricella LA, Baumgartner WA, eds. The Johns Hopkins Manual of Cardiothoracic Surgery. New York: McGraw Hill; 2007:449-67.

13. Arnrich B, Walter J, Albert A, Ennker J, Ritter H. Data mart based research in heart surgery: challenges and benefit. Stud Health Technol Inform. 2004;107: $8-12$. 
14. Albert AA, Beller CJ, Arnrich B, Walter JA, Rosendahl UP, Hetzel A, et al. Is there any impact of the shape of aortic end-hole cannula on stroke occurrence? Clinical evaluation of straight and bent-tip aortic cannulae. Perfusion. 2002;17: 451-6.

15. Albert AA, Beller CJ, Walter JA, Arnrich B, Rosendahl UP, Priss H, et al. Preoperative high leukocyte count: a novel risk factor for stroke after cardiac surgery. Ann Thorac Surg. 2003;75:1550-7.

16. Lauruschkat AH. Prevalence and risks of undiagnosed diabetes mellitus in patients undergoing coronary artery bypass grafting. Circulation. 2005;112: 2397-402.

17. Calafiore AM, Di Mauro M, Teodori G, Di Giammarco G, Cirmeni S, Contini M, et al. Impact of aortic manipulation on incidence of cerebrovascular accidents after surgical myocardial revascularization. Ann Thorac Surg. 2002;73:1387-93.

18. Kim WS, Lee J, Lee YT, Sung K, Yang J-H, Jun T-G, et al. Total arterial revascularization in triple-vessel disease with off-pump and aortic no-touch technique. Ann Thorac Surg. 2008;86:1861-5.

19. Osawa H, Inaba H, Kinoshita O, Akashi O, Minegishi S. Off-pump coronary artery bypass grafting with an aortic nonclamping technique may reduce the incidence of cerebral complications. Gen Thorac Cardiovasc Surg. 2011;59: $681-5$.

20. Assmann A, Gul F, Benim AC, Joos F, Akhyari P, Lichtenberg A. Dispersive aortic cannulas reduce aortic wall shear stress affecting atherosclerotic plaque embolization. Artif Organs. 2015;39:203-11.

21. Ura M, Sakata R, Nakayama Y, Goto T. Ultrasonographic demonstration of manipulation-related aortic injuries after cardiac surgery. J Am Coll Cardiol. 2000;35:1303-10.

22. Swaminathan M, Grocott HP, Mackensen GB, Podgoreanu MV, Glower DD, Mathew JP. The "sandblasting" effect of aortic cannula on arch atheroma during cardiopulmonary bypass. Anesth Analg. 2007;104:1350-1.

23. van der Linden J, Bergman P, Hadjinikolaou L. The topography of aortic atherosclerosis enhances its precision as a predictor of stroke. Ann Thorac Surg. 2007;83:2087-92.

24. Djaiani G, Fedorko L, Borger M, Mikulis D, Carroll J, Cheng D, et al. Mild to moderate atheromatous disease of the thoracic aorta and new ischemic brain lesions after conventional coronary artery bypass graft surgery. Stroke. 2004;35: e356-8.

25. Vallely MP, Potger K, McMillan D, Hemli JM, Brady PW, Brereton RJL, et al. Anaortic techniques reduce neurological morbidity after off-pump coronary artery bypass surgery. Heart Lung Circ. 2008;17:299-304.
26. Melduni RM, Schaff HV, Lee H-C, Gersh BJ, Noseworthy PA, Bailey KR et al. Impact of left atrial appendage closure during cardiac surgery on the occurrence of early postoperative atrial fibrillation, stroke, and mortality: a propensity score matched analysis of 10,633 patients. Circulation. 2017; $135: 366-78$

27. Raja SG, Akhtar S. Hypercoagulable state after off-pump coronary artery bypass grafting: evidence, mechanisms and implications. Exp Rev Cardiovasc Ther. 2011;9:599-608.

28. Patel JH, Stoner JA, Owora A, Mathew ST, Thadani U. Evidence for using clopidogrel alone or in addition to aspirin in post coronary artery bypass surgery patients. Am J Cardiol. 2009;103:1687-93.

29. Caplan LR, Wong KS, Gao S, Hennerici MG. Is hypoperfusion an important cause of strokes? If so, how? Cerebrovasc Dis. 2006;21:145-53.

30. Roach GW, Kanchuger M, Mangano CM, Newman M, Nussmeier N, Wolman R, et al. Adverse cerebral outcomes after coronary bypass surgery. $N$ Engl J Med. 1996;335:1857-64.

31. Glineur D, D'hoore W, de Kerchove L, Noirhomme P, Price J, Hanet C, et al. Angiographic predictors of 3-year patency of bypass grafts implanted on the right coronary artery system: a prospective randomized comparison of gastroepiploic artery, saphenous vein, and right internal thoracic artery grafts. J Thorac Cardiovasc Surg. 2011;142:980-8.

32. Glineur D, Hanet C, Poncelet A, D'Hoore W, Funken JC, Rubay J, et al. Comparison of bilateral internal thoracic artery revascularization using in situ or y graft configurations: a prospective randomized clinical, functional, and angiographic midterm evaluation. Circulation. 2008;118:S216-21.

33. Benedetto U, Caputo M, Mariscalco G, Gaudino M, Chivasso P, Bryan A, et al. Impact of multiple arterial grafts in off-pump and on-pump coronary artery bypass surgery. J Thorac Cardiovasc Surg. 2017;153:300-9.e6.

34. Novitzky D, Boswell BB. Total myocardial revascularization without cardiopulmonary bypass utilizing computer-processed monitoring to assess cerebral perfusion. Heart Surg Forum. 2000;3:198-202.

35. Halkos ME, Anderson A, Binongo JNG, Stringer A, Lasanajak Y, Thourani VH, et al. Operative strategies to reduce cerebral embolic events during on- and offpump coronary artery bypass surgery: a stratified, prospective randomized trial. $J$ Thorac Cardiovasc Surg. 2017;154:1278-85.e1.

Key Words: off-pump coronary artery bypass grafting, aortic no-touch, stroke, cardiac surgery 


\section{APPENDIX E1. METHODS \\ Statistics}

To statistically support the validity of our study results, an additional 1:1 propensity score-based case control analysis was conducted, using the nearest neighbor method with a caliper of 0.15 . The matching variables, all continuously distributed, comprised age, sex, body mass index, Canadian Cardiovascular Society class, acute coronary syndrome $<48$ hours, atrial fibrillation, American Society of Anesthesiologists class, left ventricular ejection fraction $<30 \%$, left main stenosis, peripheral and carotid artery disease, chronic obstructive pulmonary disease, serum creatinine, history of stroke, redo surgery, and emergency surgery.

After having balanced the preoperative risk variables in both groups, statistics were applied as follows: descriptive statistics are presented as mean value \pm standard error of the mean for all continuous variables. For direct comparisons of groups with continuous variables, 2-tailed Student $t$ tests or Mann-Whitney $U$ tests were performed, as indicated. Regarding categorial variables, $\chi^{2}$ tests were conducted for direct group comparisons. For continuous variables, the $95 \%$ CIs of the mean differences are presented, whereas for categorial variables, the $95 \%$ CIs of the ratio of proportions (no/yes) is given. Albeit the occurrence of postoperative stroke is a time-related event, it was analyzed as a categorial variable, because the time points of genesis and diagnosis often do not match, particularly in case of delayed awakening due to stroke. Significance was assumed if $P$ values were $<.05$. Data analysis was conducted with SPSS Statistics for Windows (IBM Corp).

\section{RESULTS}

\section{Propensity Score Matching}

Propensity score matching resulted in 3743 case-control pairs (of 8794 patients who underwent CABG with the use of CPB and 4485 anOPCAB patients). The overall balance test showed a clear balance of all covariates with $P=.5811 .^{\mathrm{E} 1}$ The relative multivariate imbalance test presented values of 0.9697 before matching and 0.9575 after matching. ${ }^{\text {E2 }}$ No covariate exhibited a large imbalance $(|\mathrm{d}|>0.25$; Table E1). The matching quality was further confirmed using receiver operating characteristic curve analysis (area under the curve $0.52 ; 95 \% \mathrm{CI}, 0.51-0.53$ ).
A comparison of all individual preoperative variables did not reveal any statistically significant difference between anOPCAB and CPB patients (Table E2).

\section{Postoperative Outcome Characteristics in anOPCAB Versus On-Pump CABG Patients}

$A n O P C A B$ resulted in a significant reduction of the postoperative overall stroke risk $(0.45 \%$ vs $1.28 \%$ in CPB patients; $P=.0001$; Table E3). When dividing strokes into early and delayed strokes, anOPCAB was shown to significantly reduce the probability that a stroke occurs as an early stroke $(17.6 \%$ vs $64.6 \%$ in CPB patients with $P=.0009$ and $\mathrm{OR}=8.5$ with $95 \% \mathrm{CI}, 2.14-33.8)$. The early stroke rate after anOPCAB amounted to $0.08 \%$ ( $95 \% \mathrm{CI},-0.01 \%$ to $0.17 \%)$ versus $0.83 \%(95 \% \mathrm{CI}$, $0.54 \%-1.12 \%)$ in CPB patients $(P<.0001)$, whereas delayed strokes were not significantly reduced $(0.37 \%$ $[95 \% \quad \mathrm{CI}, \quad 0.18 \%-0.57 \%]$ vs $0.46 \% \quad[95 \% \mathrm{CI}$, $0.24 \%-0.67 \%]$ ) in anOPCAB versus CPB patients, respectively $(P=.5749)$.

Direct group comparisons between anOPCAB and CPB CABG patients were conducted to analyze the outcome in dependency on the surgical technique (Table E2). The occurrence of cardiopulmonary resuscitation or rethoracotomy was significantly lower, whereas the creatinine levels were higher after anOPCAB. The 30-day mortality was equal between the 2 groups.

\section{E-References}

E1. Hansen BB, Bowers J. Covariate balance in simple, stratified and clustered comparative studies. Stat Sci. 2008;23:219-36.

E2. Iacus SM, King G, Porro G. Multivariate matching methods that are monotonic imbalance bounding. J Am Stat Assoc. 2011;106:345-61. 


\section{Stroke Occurrence (1998-2004)}

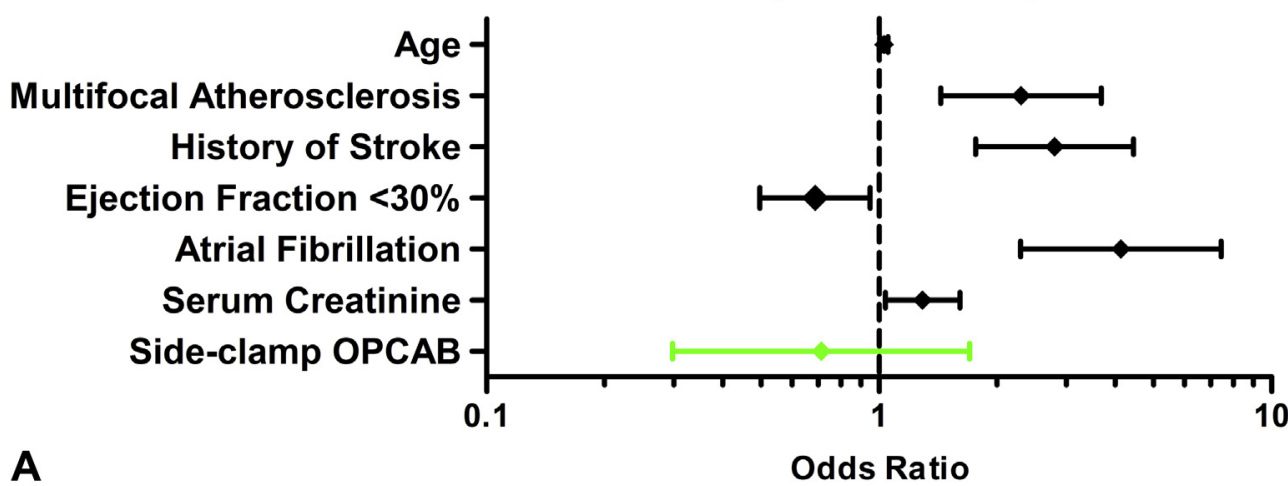

Early Stroke Prevention (1998-2004)

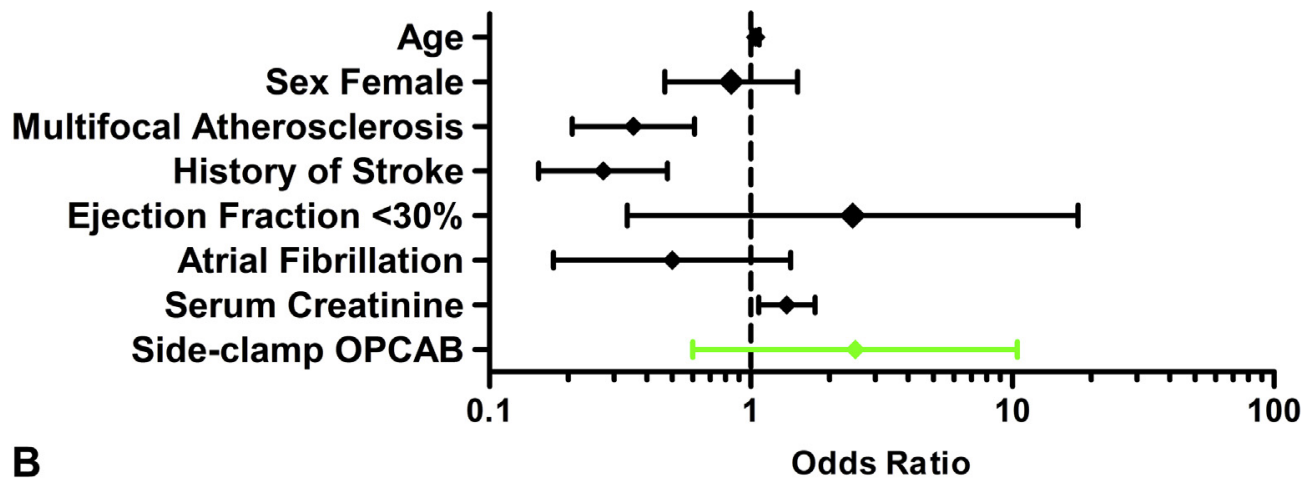

Delayed Stroke Prevention (1998-2004)

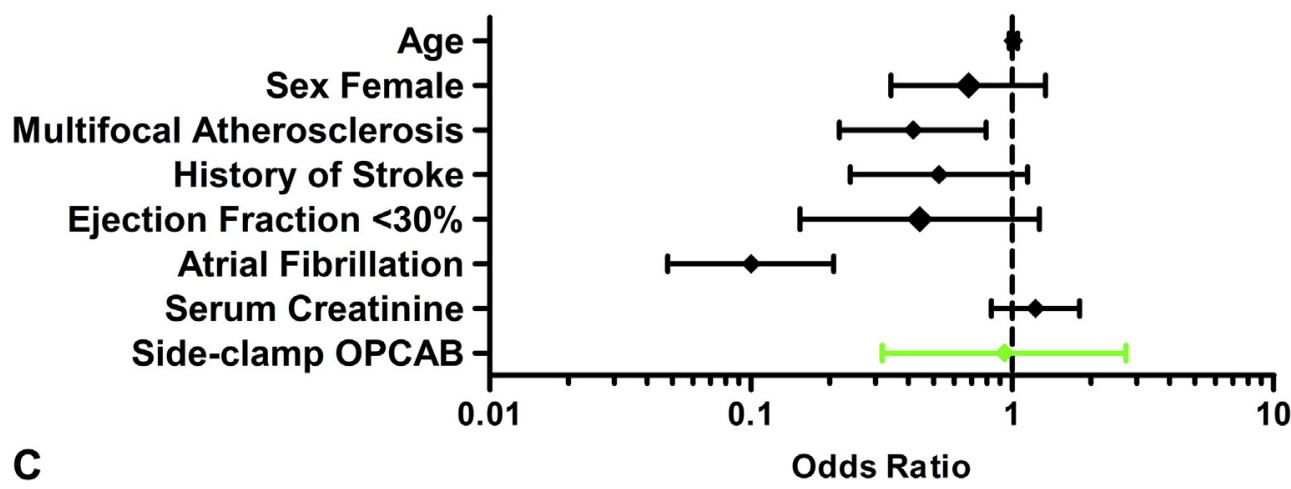

FIGURE E1. Risk factors for (A) stroke, (B) early stroke, and (C) delayed stroke before introduction of anOPCAB (1998-2004). Side-clamp OPCAB does not prevent early or delayed strokes. Confirmation of well described stroke risk factors. OPCAB, Off-pump coronary artery bypass grafting. 


\section{Stroke Occurrence (2005-2014)}

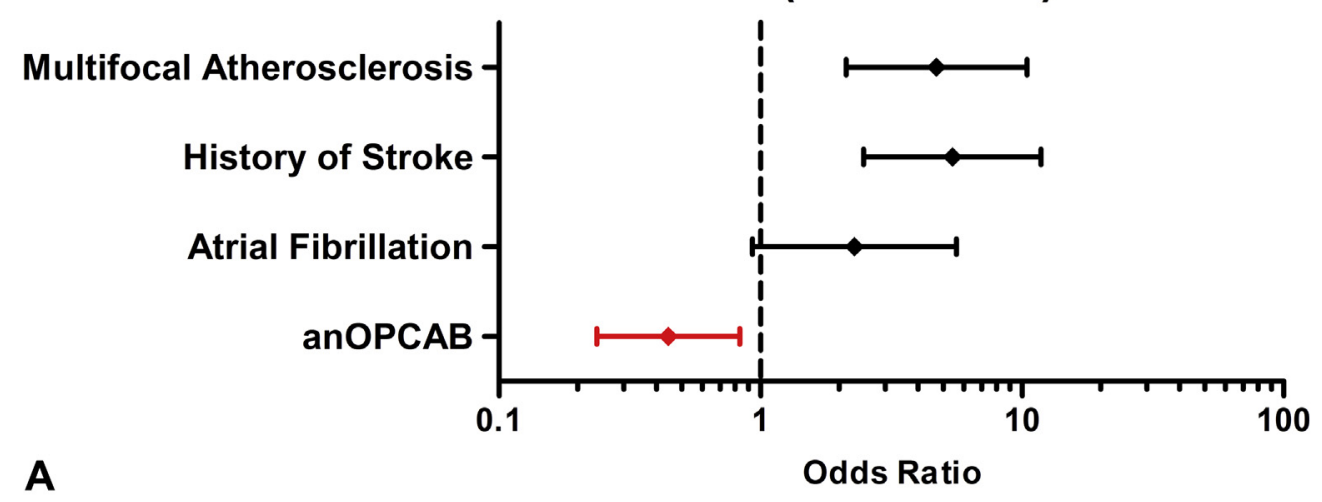

\section{Early Stroke Prevention (2005-2014)}

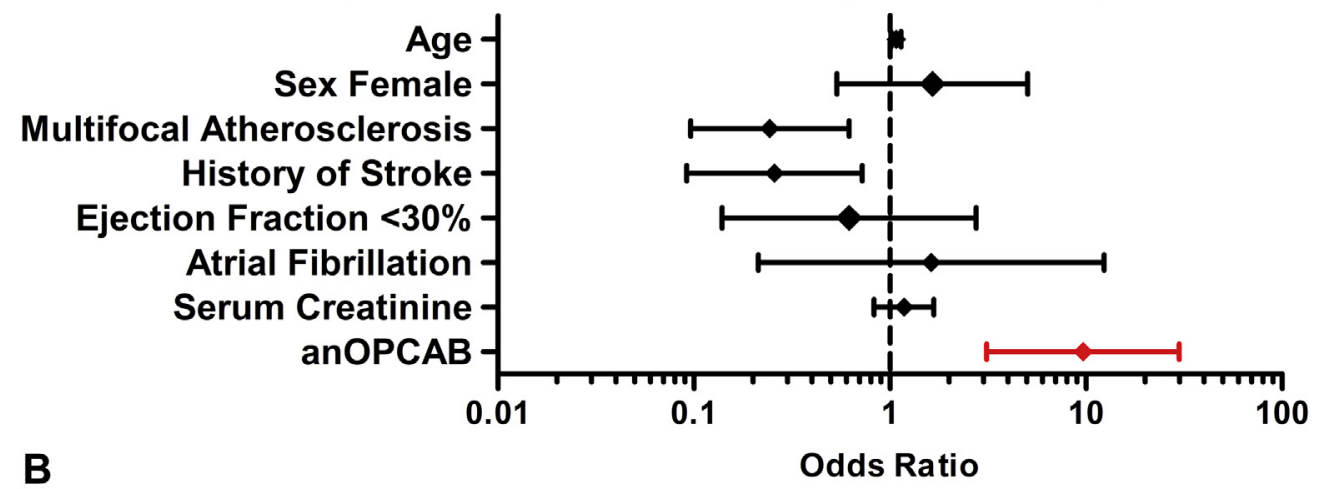

\section{Delayed Stroke Prevention (2005-2014)}

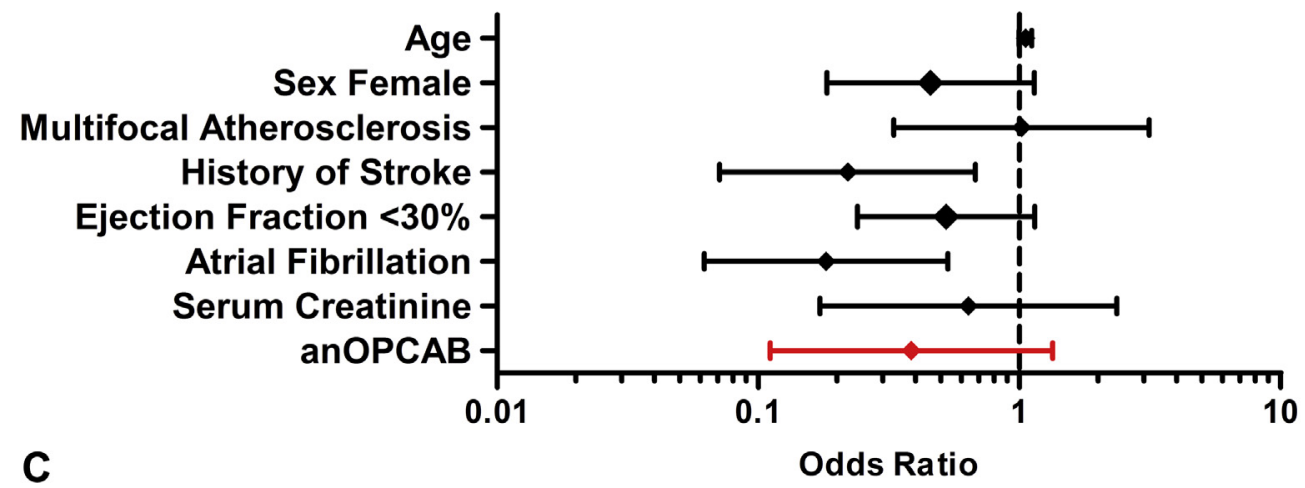

FIGURE E2. Risk factors for (A) stroke, (B) early stroke, and (C) delayed stroke after introduction of anOPCAB (2005-2014). anOPCAB prevents strokes in general and early but not delayed strokes. Confirmation of well described stroke risk factors. anOPCAB, Anaortic off-pump coronary artery bypass grafting. 
TABLE E1. Balance results for covariates in propensity score matching (1998-2014; 3743 pairs)

\begin{tabular}{|c|c|c|}
\hline \multirow[b]{2}{*}{ Covariate } & \multicolumn{2}{|c|}{ Standardized mean difference } \\
\hline & Before matching & After matching \\
\hline Propensity & 0.844 & 0.073 \\
\hline Age & 0.045 & 0.010 \\
\hline Sex female & -0.077 & -0.011 \\
\hline BMI & 0.041 & 0.019 \\
\hline $\mathrm{CCS} \geq 2$ & -0.047 & -0.035 \\
\hline ACS $<48 \mathrm{~h}$ & -0.057 & -0.007 \\
\hline $\mathrm{AF}$ & -0.005 & -0.011 \\
\hline $\mathrm{ASA} \geq 4$ & 0.010 & 0.013 \\
\hline LVEF $<30 \%$ & 0.210 & -0.004 \\
\hline LMS & 0.220 & 0.027 \\
\hline Redo surgery & 0.139 & 0.021 \\
\hline $\mathrm{CAD} / \mathrm{PVD}$ & -0.048 & -0.026 \\
\hline PVD & 0.014 & -0.025 \\
\hline COPD & -0.359 & -0.013 \\
\hline Creatinine & -0.104 & -0.034 \\
\hline Stroke & 0.015 & -0.001 \\
\hline Emergency CABG & -0.035 & -0.022 \\
\hline
\end{tabular}

BMI, Body mass index; CCS, Canadian Cardiovascular Society classification; $A C S$, acute coronary syndrome; $A F$, atrial fibrillation; $A S A$, American Society of Anesthesiologists classification; $L V E F$, left ventricular ejection fraction; $L M S$, left main stenosis; $C A D$, carotid artery disease; $P V D$, peripheral vascular disease; $C O P D$, chronic obstructive pulmonary disease; $C A B G$, coronary artery bypass grafting.
TABLE E2. Baseline characteristics of patients undergoing anOPCAB versus on-pump CABG after propensity score matching

\begin{tabular}{|c|c|c|c|}
\hline Variable & $\begin{array}{r}\text { anOPCAB } \\
(\mathrm{n}=3743)\end{array}$ & $\begin{array}{c}\text { CPB } \\
(\mathrm{n}=\mathbf{3 7 4 3}) \\
\end{array}$ & $\begin{array}{c}P \\
\text { value }\end{array}$ \\
\hline Age, y & $66.4 \pm 0.16$ & $66.3 \pm 0.15$ & .6537 \\
\hline Female sex, $\%$ & 21.9 & 22.3 & .6358 \\
\hline BMI & $28.3 \pm 0.08$ & $28.2 \pm 0.07$ & .4013 \\
\hline $\mathrm{ASA} \geq 4, \%$ & 24.0 & 23.2 & .6593 \\
\hline CPR $<48$ h, \% & 0.16 & 0.03 & .0587 \\
\hline ACS $<48$ h, \% & 14.7 & 14.9 & .7695 \\
\hline LVEF $<30 \%, \%$ & 3.6 & 3.7 & .7109 \\
\hline $\mathrm{CCS} \geq 2, \%$ & 13.5 & 14.7 & .0668 \\
\hline LMS, \% & 25.7 & 24.4 & .2199 \\
\hline $\mathrm{AF}, \%$ & 3.7 & 4.0 & .6307 \\
\hline Stroke, $\%$ & 8.3 & 8.3 & .9666 \\
\hline CAD/PVD, \% & 17.0 & 17.9 & .2729 \\
\hline $\mathrm{CAD}, \%$ & 11.1 & 10.4 & .3132 \\
\hline PVD, \% & 9.7 & 10.4 & .2822 \\
\hline COPD, $\%$ & 10.5 & 10.8 & .6001 \\
\hline DM II, \% & 31.8 & 29.8 & .0640 \\
\hline Creatinine, $\mathrm{mg} / \mathrm{dL}$ & $1.08 \pm 0.01$ & $1.11 \pm 0.01$ & .0820 \\
\hline Emergency CABG, \% & 9.4 & 10.0 & .3682 \\
\hline
\end{tabular}

anOPCAB, Anaortic off-pump coronary artery bypass grafting; $C P B$, cardiopulmonary bypass; $B M I$, body mass index; $A S A$, American Society of Anesthesiologists classification; $C P R$, cardiopulmonary resuscitation; $A C S$, acute coronary syndrome; $L V E F$, left ventricular ejection fraction; $C C S$, Canadian Cardiovascular Society classification; $L M S$, left main stenosis; $A F$, atrial fibrillation; $C A D$, carotid artery disease; $P V D$, peripheral vascular disease; $C O P D$, chronic obstructive pulmonary disease; $D M I I$, diabetes mellitus type II; $C A B G$, coronary artery bypass grafting.

TABLE E3. Outcome of patients undergoing anOPCAB versus on-pump CABG after propensity score matching

\begin{tabular}{lccr}
\hline \multicolumn{1}{c}{ Variable } & $\begin{array}{c}\text { anOPCAB } \\
(\mathbf{n}=\mathbf{3 7 4 3})\end{array}$ & $\begin{array}{c}\text { CPB } \\
(\mathbf{n}=\mathbf{3 7 4 3})\end{array}$ & $\begin{array}{r}\boldsymbol{P} \\
\text { value }\end{array}$ \\
\hline Stroke, \% & 0.45 & 1.3 & $\mathbf{. 0 0 0 1}$ \\
$\quad$ Major stroke, \% & 0.31 & 1.0 & $<. \mathbf{0 0 0 1}$ \\
Early stroke, \% & 0.08 & 0.83 & $<.0001$ \\
$\quad$ Major early stroke, \% & 0.05 & 0.65 & $<.0001$ \\
\hline Delayed stroke, \% & 0.37 & 0.46 & .5749 \\
$\quad$ Major delayed stroke, \% & 0.26 & 0.39 & .3247 \\
CPR, \% & 1.1 & 1.9 & $\mathbf{. 0 0 6 0}$ \\
\hline Rethoracotomy, \% & 1.6 & 2.5 & $\mathbf{. 0 0 6 0}$ \\
\hline Reintubation, \% & 2.0 & 2.5 & .1370 \\
\hline Creatinine, mg/dL & $1.26 \pm 0.02$ & $1.18 \pm 0.02$ & $\mathbf{. 0 0 1 0}$ \\
CVVHDF, \% & 3.9 & 3.2 & .1326 \\
\hline 30-Day mortality, \% & 1.3 & 1.6 & .2448 \\
\hline$P$ values indicating statistically significant differences are in bold. & anOPCAB, \\
Anaortic off-pump coronary artery bypass grafting; $C P B$, cardiopulmonary bypass; \\
$C P R$, cardiopulmonary resuscitation; $C V V H D F$, chronic veno-venous hemodiafiltra- \\
tion.
\end{tabular}

